\title{
Formação cultural e sociedade de consumo - apontamentos oriundos de uma pesquisa-ação
}

\author{
Cultural formation and consumption society - notes arising from an \\ action research
}

Thaís de Oliveira Nabaes*

Universidade Federal do Rio Grande

Resumo Visando problematizar aspectos das sociedades hodiernas no que diz respeito aos seus processos de formação cultural, o presente texto apresenta considerações oriundas de uma pesquisa-ação, que teve como referencial principal a Teoria Crítica de matriz frankfurtiana. As manifestações musicais de um grupo de alfabetizandos foram escolhidas como um recorte da realidade social, a fim de discutir fenômenos de consumo e descartabilidade de bens, em especial os culturais. No contexto do trabalho de campo, as categorias emergentes possibilitaram uma ampla discussão sobre elementos envolvidos nos processos de formação cultural nas sociedades marcadas pelo signo do consumo.

PALAVRAS-CHAVE: Educação; Formação cultural; Sociedade de consumo.

Abstract Aiming to discuss aspects of contemporary societies about to their processes of cultural formation, this article presents considerations arising from an action research, which had as main reference Frankfurt School Critical Theory. The musical manifestations of a group of literacy learners were chosen as a part of social reality in order to discuss the phenomena of consumption and disposability of goods, especially cultural ones. In the context of fieldwork, emerging categories allowed a wide discussion on elements involved in the processes of cultural formation in societies marked by the sign of consumption.

KEYWORDS: Education; Cultural formation; Consumption society. 


\section{Apresentação da temática e orientações metodológicas}

O estudo que ora apresentamos origina-se de pesquisa que se propôs a investigar processos de formação cultural gestados em sociedades capitalistas. Por ser uma discussão ampla, tal estudo delimitou-se a partir de um recorte da realidade: foram eleitas algumas manifestações musicais da contemporaneidade como motivadoras de debates com um grupo de vinte e três alfabetizandos de uma escola no município de Rio Grande/RS.

A pesquisa discutiu aspectos culturais da chamada "Sociedade de Consumo", elegendo categorias de análise a partir de algumas manifestações musicais que têm se constituído como objetos recorrentes de fruição estética. Considerando a intervenção maciça dos meios de comunicação social na formação do ouvinte/ receptor das obras, os aportes teóricos e análises voltaram-se aos fenômenos de consumo e descartabilidade de bens com que nos deparamos nas sociedades hodiernas, inclusive os culturais.

Se considerarmos que "a Música não escapa à reificação" (MERQUIOR, 1969 , p. 60), compreenderemos que o apelo de determinadas produções não estão relacionados apenas às suas possibilidades de comercialização, mas à própria necessidade de compor uma matriz ideológica e psicológica que sustente algumas bases para a retroalimentação do sistema capitalista. A este respeito, Adorno acrescenta que “[...] ao invés de entreter, parece que tal música contribui ainda mais para o emudecimento dos homens, para a morte da linguagem como expressão, para a incapacidade de comunicação" (2000, p. 67).

Partindo da questão de pesquisa ${ }^{1}$ e das experiências estético-musicais dos sujeitos empíricos, consideramos que os pressupostos metodológicos eleitos deveriam nos aprimorar no exercício da escuta. No contexto deste estudo, a escuta foi entendida em seus sentidos literal e metafórico, percebendo a escola em "suas redes de significação, seus processos constitutivos, enxergando-a como um espaço sociocultural atravessado pela ótica da(s) diferente(s) cultura(s) presentes em uma sociedade multicultural como a nossa" (TAVARES, 2003, p. 45).

Ao procurar discutir as margens de escolha na sociedade contemporânea, nos deparamos com a situação de dialogar com um grupo de crianças no início de suas vidas escolares. Sendo o comportamento adulto a grande referência do aprendizado na infância, foi preciso entender o processo de apropriação de identidade cultural de forma mais ampla, não apenas pautado pelas referências parentais. Adorno (2000) destaca que há apropriação imitativa de modelos também entre ouvintes mais experientes, chegando a considerar a existência de uma coação coletiva da música. Segundo o mesmo autor, "os ouvintes e os consumidores em geral precisam e exigem exatamente aquilo que lhes é imposto insistentemente” (id., p. 90).

Considerando as características deste estudo, bem como os caminhos metodológicos que nos guiaram no desdobramento da questão de pesquisa, o situamos entre as abordagens de pesquisa qualitativa, aproximando-o especificamente da pesquisa-ação. $\mathrm{Na}$ seleção dos materiais de análise, tivemos como critério destacar as si- 
tuações em que foi observado maior engajamento do grupo no que tangia à temática de consumo de bens culturais, especificamente o de música². Assim, optamos por registros escritos, entrevistas, oficinas musicais, gravações de vídeo e áudio em diferentes locações e datas, palestras, conversas dirigidas, organização de uma feira de CDs, além do diário de campo.

\section{Horizontes Teóricos}

A Teoria Crítica desenvolvida pelos filósofos da Escola de Frankfurt se constituiu no principal referente deste estudo, em especial as contribuições de Theodor Adorno, ensaísta e também crítico musical. Trabalhando temas como Indústria Cultural, sociedade de consumo e formação política, seus escritos lançam luz ao perigo da sociedade de informação nos conduzir à barbárie dos sentidos, algo que aparece refletido em diversos espectros das relações humanas. Nesta perspectiva, ao empreender uma crítica radical à cultura moderna, Adorno e os frankfurtianos propuseram um novo aparato filosófico que investigasse as contradições internas da história do pensamento (TIBURI, 1995).

Considerando fracassado o projeto de autonomia da razão e tomando como exemplo as grandes barbáries do século XX - em especial Auschwitz, a Teoria Crítica ensaiou uma aproximação de suas bases com alguns fundamentos psicanalíticos. Auschwitz foi a concretização da idéia de que os ditames da razão não foram capazes de resolver os conflitos e os reflexos de uma sociedade pautada pelo autoritarismo e massificação de consciências.

A concepção de que a civilização é fruto da frustração dos instintos é compartilhada por Adorno, e este fato poderia explicar a agressividade na cultura contemporânea. A coesão social necessária a um projeto de dominação de grande alcance - como ocorreu na ascensão do nazismo na Alemanha -, sugere a existência não apenas de uma ideologia operante, mas de mecanismos psicológicos de repressão, identificação e projeção patológica que acabam se tornando uma sofisticada regulação das atividades da mente.

O resgate da razão emancipatória, considerada a utopia dos frankfurtianos, fiel ao propósito iluminista de "livrar os homens do medo e investí-los na posição de senhores" (HORKHEIMER \& ADORNO, 1985, p. 19), aparece como base da Teoria Crítica. Daí a necessidade de ocupar-se do questionamento de "tudo aquilo que ofusca o poder da consciência, o espaço da liberdade, a afirmação da individualidade e da autonomia do homem" (PUCCI, 2007, p. 30).

A partir destes referenciais, empreendemos a tarefa de compor uma matriz esquemática, aprofundando algumas categorias teóricas, conforme é possível visualizar a seguir: 
Figura 1- Categorias Teóricas.

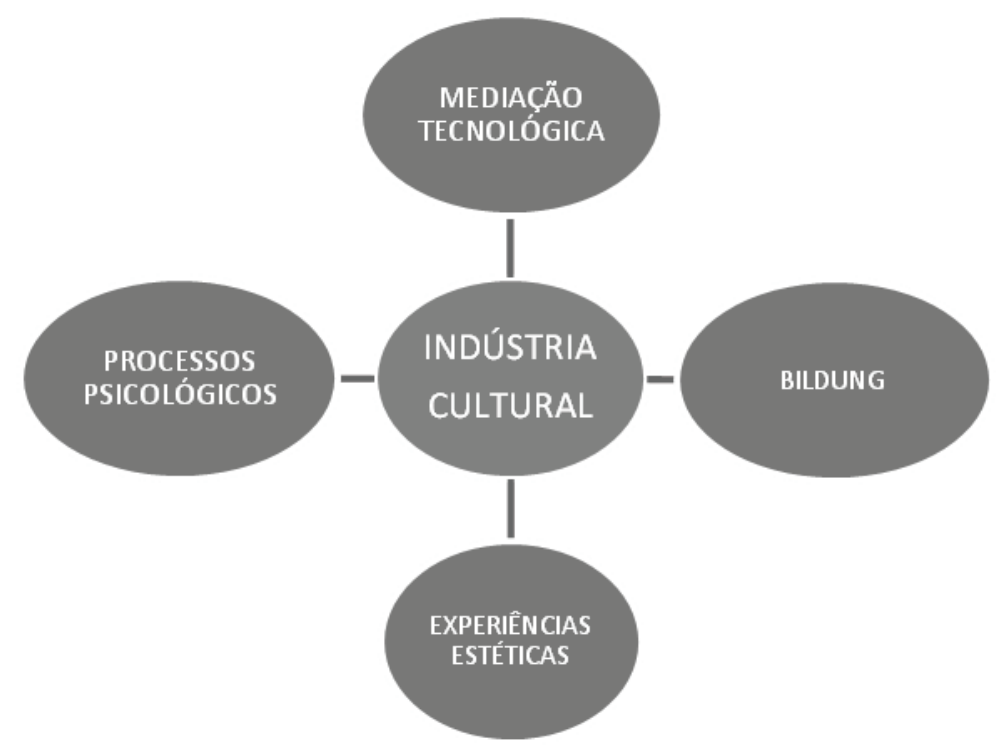

A partir de um grande eixo denominado de Indústria Cultural, delineouse uma reflexão sobre os seguintes temas:

- Mediação Tecnológica: relacionado a acepções quanto à expansão quantitativa dos bens culturais, especialmente a partir do desenvolvimento e acesso às novas tecnologias de informação;

- Processos Psicológicos: aproximações da Teoria Crítica com o referencial psicanalítico, em especial os mecanismos de identificação e projeção, necessários à adesão aos hábitos e produtos apresentados pela sociedade de consumo;

- Experiências Estéticas: reflexões a respeito do lugar que as experiências estéticas promovidas pela Indústria Cultural têm ocupado nas sociedades contemporâneas;

- Bildung: apontamentos sobre o conceito de Formação Cultural em Adorno e processos de semiformação. de campo:

A figura abaixo, por sua vez, ilustra as categorias emergentes do trabalho 
Figura 2- Categorias Emergentes no trabalho de campo

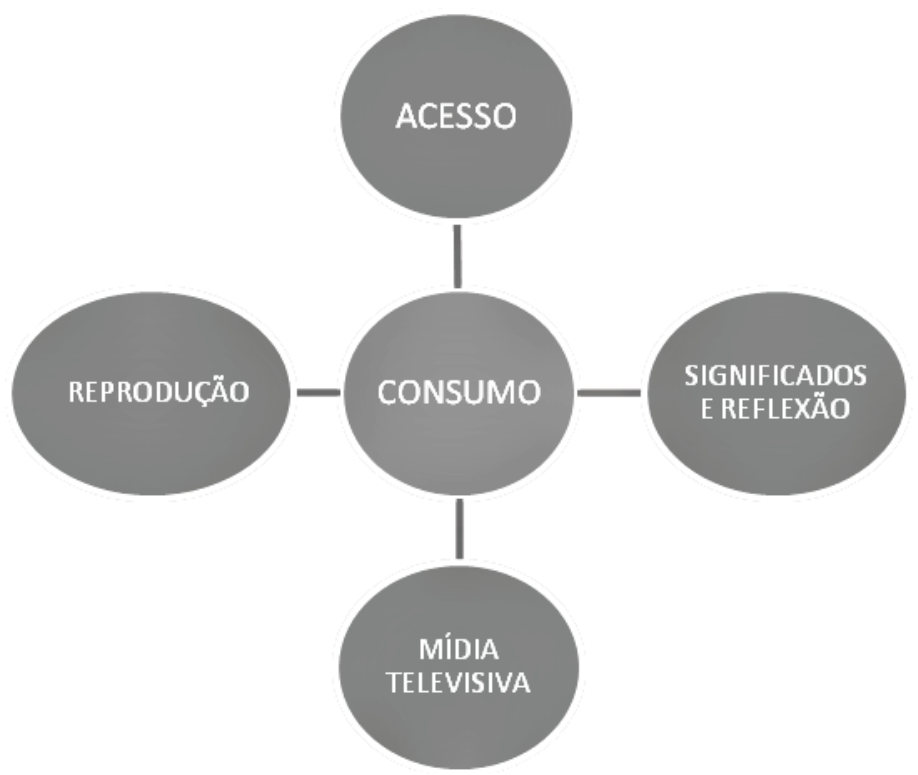

A partir do signo Consumo desdobraram-se outras categorias, a partir da análise dos dados emergentes no trabalho de campo. Em linhas gerais, é possível apresentá-los da seguinte forma:

- Acesso: referente às principais vias pelas quais o grupo chegou às produções musicais mencionadas nos relatos;

- Reprodução: aprofundamento da reflexão a respeito da formação dos padrões de escolha de escuta, diante das experiências estético-musicais que os sujeitos descreveram e/ou manifestaram;

- Mídia televisiva: relacionada com as duas anteriores, entendendo que a televisão se faz um meio facilitador de grande alcance na difusão de determinadas produções musicais;

- Significado e reflexão: discussão sobre o significado que o grupo atribuía ao que estava sendo dito (em letras de música), bem como a respeito da participação neste processo de reprodução.

Na sequência deste texto, serão expostos momentos de discussão que foram problematizados na pesquisa, com destaque para alguns dos diálogos que mais elucidaram as questões postas para tal.

\section{As vozes dos alfabetizandos}

O caráter de mercadoria que as manifestações artísticas têm por vezes assumido no contexto das sociedades capitalistas está intimamente relacionado, con- 
forme aponta Benjamin (1980), às suas possibilidades de reprodução técnica, devido ao aparato tecnológico que estas mesmas sociedades foram capazes de desenvolver. A tipografia, a fotografia e a arte cinematográfica revolucionaram as formas de divulgação e de produção das obras de arte, o que significou um aumento expressivo nas possibilidades de acesso, assim como suscitaram novas formas de apreciação estética.

A preocupação quanto à circunstância administrada de mundo, onde se desenvolve uma unicidade conceitual e uma identificação indiscriminada - uma absolutização da imitação, segundo Adorno (2000) - leva Benjamin a afirmar que:

$\mathrm{Na}$ medida em que se diminui a significação social de uma arte, assiste-se, no público, a um divórcio entre o espírito crítico e o sentimento de fruição. Desfruta-se do que é convencional, sem criticá-lo; o que é verdadeiramente novo, critica-se a contragosto. (BENJAMIN, 1980, p. 21).

No contexto desta pesquisa, foi possível observar que não eram necessárias muitas audições para que letras de música (e respectivas coreografias) fossem decoradas. Inclusive algumas destas experiências já estavam sendo forjadas como as principais referências de escuta do grupo. Dentre o que foi mais citado nos encontros com o grupo, destacamos como exemplos:

A) "Créu": funk centrado na coreografia e no refrão de uma só palavra. O compositor tem um site em que exalta o espaço que teve na mídia para a divulgação de seu trabalho. O site também revela a participação do compositor/DJ em projetos voltados para a infância, dada a sua popularidade com crianças de cinco a doze anos.

Numa das discussões, questionamos as crianças sobre o significado de créu. A primeira resposta foi que se trata de um tipo de dança. Outra criança explicou que "créu" queria dizer dançar até o chão (ALUNA 9), encenando. Indagamos sobre as dançarinas: por que não estavam de vestido? Então dialogamos:

ALUNO 1: - Elas botam uma roupa pequena pra se exibir.

ALUNA 9: - A música é feia e as mulheres ficam feias.

ALUNO 4: - O Silvio Santos manda vestir as roupas porque ele é o dono. [...]

ALUNA 9:- O Silvio Santos acha as mulheres gostosas.

PROFESSORA: - O que é gostosa?

ALUNA 9: (risos) - Gostosa é bonita

(Diálogos)

B) "Voltei": Pagode cantado pelo grupo Molejo, cujo refrão diz: "Vou voltar pra sacanagem, pra casa de massagem/ ali sempre foi meu lugar/Já tava (sic) com saudade das velhas amizades/ hoje vou me embriagar". A questão que alguns alunos e a professora frequentemente levantavam era o significado de "casa de massagem". Tal expressão era entendida pelo grupo pela simples junção das palavras "casa" e "massagem”. A reprodução de letras sem compreensão do significado foi muito evidente nesta canção, como se pode observar nestas falas: 
PROFESSORA: [...] o que era casa de massagem?

ALUNO 3: é fazer massagem

$[\ldots]$

ALUNO 2: É ... ELE COPIOUDA MÚSICA

PROFESSORA: Tu copiou (sic) da música, [...]? Tá mas vocês tão (sic) cantando a música, vocês não tão (sic) entendendo o que vocês tão (sic) cantando?

ALUNA 11: EU COPIEI

ALUNO 2: EU SÓ COPIEI

PROFESSORA: Mas é assim, a gente canta qualquer coisa, sem saber o que quer dizer, sem conhecer, sem entender o que é?

ALUNO 8: EU NÃO PRECISO ENTENDER, SÓ PRECISO COPIAR E PRONTO.

(Transcrição mp3)

A repetição de algo do qual não se tem completa compreensão foi um dado bastante comum no trabalho de campo. Era até previsível que grande parte das crianças tivesse esta postura, pois a própria faixa etária as situa em outras zonas de interesse que não os estritamente sexuais, como é o caso da letra acima mencionada. Uma das questões que mais nos inquietava nestes momentos era o papel da escola em termos de formação cultural, uma concepção que ultrapassa a veiculação de informação conteudística. Como reverter um quadro que já se delineava: crianças sinalizando a construção de um habitus de apreciação estética de canções que por vezes veiculam obscenidades, desprestígio à figura feminina, entre outros?

Ainda dentre os materiais de análise selecionados para este texto, destacamos como último exemplo:

C) "Amigo fura-olho": canção interpretada pelo cantor Latino e pelo $r a-$ pper Daddy Kall. A letra fala de uma traição entre amigos, onde um se envolveu com a mulher do outro. É uma letra extensa, cheia de rodeios até a revelação do "triângulo". Em uma de nossas conversas gravadas, pudemos perceber que algumas crianças interpretavam que era uma atitude "errada" o fato da traição, porém não possuíam entendimento completo do que acontecia quando o homem e a mulher saíam. Mais uma vez, ocorria a pura reprodução da letra. Um aluno demonstrou perceber do que se tratava, mas não quis se manifestar:

COLABORADOR: Tá e essa música aí, o que (...) quer dizer?

ALUNO 4: é que... o latino pegou a mulher do daddy kall, né [...]?

$[\ldots]$

ALUNO 5: pegou pra sair

PROFESSORA: Ah ele saiu com ela

$[\ldots]$ mas ele saiu pra ir aonde? 
ALUNO 4: não sei

ALUNO 8: namorar

ALUNO 3: [...] numa festa

$[\ldots]$

PROFESSORA: pra namorar?

VOZES: não

ALUNO 8: é, namorar... ele roubou a mulher do outro, namorou com a mulher do outro se eles já tinham casado

ALUNO 4: [...] Eles ficaram fazendo amor na cama deitado, não sei fazendo

[...]

ALUNO 5: eu sei

$[\ldots]$

PROFESSORA: tu sabes, [...]?

$[\ldots]$

ALUNO 5: NÃO POSSO FALAR

PROFESSORA: por quê?

\section{ALUNO 5: É MUITO DE ADULTO}

(Transcrições mp3)

Maia \& Antunes $(2008)^{3}$ discorrem sobre a limitação da consciência como decorrência da adesão voluntária à lógica da dominação, algo que condiz com o que Adorno denominou como regressão da audição. Os autores questionam se há liberdade de escolha em um contexto que se caracteriza pela "estandardização, facilitação, banalidade e vulgaridade" (id, p.3). Se observarmos atentamente, o que surge nos depoimentos das crianças é a exaltação da popularidade das canções ou da performance dos intérpretes. As escolhas estão bastante relacionadas ao que é amplamente divulgado nos meios de comunicação, em especial na televisão, dado o predomínio das sensações visuais em nossa sociedade, "que deixam nossas relações com a música próximas das reações inconscientes” (MAIA; ANTUNES, 2008, p. 29).

A grande preocupação a respeito deste tema é que esta passividade na escuta seja estendida à conduta social, pois "o potencial destrutivo da cultura administrada acaba por inviabilizar práticas emancipatórias ao exterminar a reflexão crítica, na medida em que mina as bases sociais objetivas que permitiriam aos indivíduos realizá-la". (MAIA \& ANTUNES, 2008, p. 5). ${ }^{4} \mathrm{O}$ fato de as letras aqui expostas estarem envoltas em uma atmosfera rítmica e melódica que o grupo considerava agradáveis aos seus ouvidos, não impediu que alguns tivessem a percepção de que em algumas delas havia algo de desagradável ou inadequado:

ALUNA 9: Tem muitas músicas que não podemos copiar e cantar, pois tem muitas bobagens que não é pra criança falar.

(Anotações aula) 
ALUNA 5: (...) eu pensei numa parte que.., eu acho esqueceram dessa parte e eu acho que essa parte é feia

[...]

PROFESSORA: qual parte?

ALUNO 8: é uma parte que ele fala...

ALUNO 4: palavrão

ALUNO 8: ele fala covarde só [...]

ALUNA 5: é... Covarde

$[\ldots]$

PROFESSORA: covarde? É a pior parte dessa música?

ALUNO 8: ele fala... As partes que eu não canto é (sic) as partes do covarde $[\ldots]$

\section{PROFESSORA: por que que (sic) tu não cantas essa parte?}

\section{ALUNA 5: porque éfeia}

$[\ldots]$

\section{ALUNO 8: é que eu já entendi quase toda a música}

\section{(Transcrição mp3)}

Observamos que havia certo constrangimento ao cantarem estes trechos que apontaram, mesmo quando julgavam que a professora não estava ouvindo. Não se importavam de cantar o Créu, que para o grupo era só um som aleatório, mas covarde eles sabiam o que queria dizer, por isso evitavam a palavra. Isto foi muito recorrente nas observações. Havia uma espécie de restrição ao que eles consideravam como "palavra feia”, e quando alguém cantava, era repreendido pelo grupo.

A questão que se pauta a partir disso é a promoção de uma Educação (não apenas estético-musical) que nos habilite a fazer outras escolhas. Falamos em escolhas que não tolham as liberdades individuais, nem a percepção do Bom e Belo, tão obscurecida pelos subprodutos da Indústria Cultural. Não se trata aqui de tapar os olhos frente ao que consideramos inadequado, mas poder ter outros referenciais, que não apenas os insistentemente "oferecidos" por um determinado grupo (seja ele ou não o ideologicamente dominante). É preciso que se faça o "protesto do particular frente à generalidade" (PUCCI et alii, 2008 p. 59), especialmente quando isto diz respeito à arte, em que há a "possibilidade do prazer onde cessa a mera aparência"'. Caso contrário, continuaremos alimentando as engrenagens da semiformação, supostamente horrorizados com algo que, de tão corriqueiro, se tornou parte de nossas vidas.

\section{À guisa de conclusão}

Ressalta-se que a discussão sobre a produção uniformizada de bens simbólicos é um esforço que exige o despojamento de algumas ideias pré-concebidas, e o reconhecimento de que muito do que temos "aceitado" como produção e retrato de um 
extrato social específico, não foi necessariamente criado por este grupo, mas fabricado para seu consumo. Aqui se desmascara a ideia de cultura de massa, pois ela não é feita pela dita "massa" e sim para ela. Nisto reside uma das obviedades da Indústria Cultural, o fato de estar intimamente ligada ao modo de produção econômico dominante. Conforme Costa,

Ao contrapor ao conceito de comunicação de massa à categoria Indústria Cultural, Horkheimer e Adorno acusaram a natureza da produção industrial de uma cultura que não é feita pela "massa", e que corresponde a mecanismos de seriação e segmentação de bens culturais produzidos de forma parcelar e para públicos diferenciados a escala social. Ou seja, a produção da cultura, da arte, dos bens simbólicos, assume uma relação direta com o modelo de produção material. (COSTA, 2007, p. 181).

Feitas esta considerações, destacamos que o termo Indústria Cultural aparece na Dialética do Esclarecimento como uma crítica à totalidade, onde os instrumentos de dominação $0^{6}$ acabam por converter os homens em "meros seres genéricos, iguais uns aos outros pelo isolamento na coletividade governada pela força" (HORKHEIMER \& ADORNO, 1985, p. 47).

Fazendo um paralelo com o contexto industrial, em que a rotina dos trabalhadores é padronizada pelas necessidades de produção, Adorno e Horkheimer utilizam o vocábulo indústria no âmbito da vida cultural para indicar que também esta é passível de ideologização e controle. Da mesma maneira em que o mercado vende os bens de consumo, a Indústria Cultural "vende" os produtos culturais, também como condição de afiliação social e meio para a universalização de uma ideologia dominante. Neste processo, continuamente se reafirma o que está posto, com a destituição da singularidade do indivíduo pela assunção muitas vezes irrefletida dos modelos que lhe são oferecidos.

É um mecanismo em que, pela repetição do sempre mesmo, não se cogitam outras formas de vida social. Algo como conservar cada qual no seu lugar, cada grupo na posição social que já ocupa, fenômeno que Fabiano denomina como um "processo manipulativo da cultura no ambiente da sociedade industrial” (2001, p. 137).

Para Adorno, "o alimento que a indústria cultural oferece aos homens permanece como pedra da estereotipia” (ADORNO, 2002, p. 47). Daí que se forme, através da Indústria Cultural, um sistema de relações que coincide com um "instrumento hipersensível de controle social" (id., p. 48-49), onde "a escala do teor de vida corresponde exatamente ao elo íntimo das castas e dos indivíduos com o sistema” (id., p.49). A este respeito, temos também em Marcuse uma crítica a uma sociedade que se faz unidimensional:

Nesta sociedade, o aparato produtivo tende a tornar-se totalitário no quanto determina não apenas as oscilações, habilidades e atitudes socialmente necessárias, mas também as necessidades e aspirações individuais. Oblitera assim a oposição entre existência privada e pública, entre necessidades individuais e sociais. A tecnologia serve para instituir formas novas, mais eficazes e mais agradáveis de controle social e coesão social. (MARCUSE, 1982, p. 18). 
Daqui se compreende a origem e existência dos discursos que endossam a veiculação nas escolas (nos horários de recreio ou em festas comunitárias, por exemplo) de determinados hits inadequados para a apreciação infantil, sob a justificativa de que "é o que eles gostam de ouvir". Será que é uma escolha soberana entre outras tantas opções? O que se pretende no incentivo a este tipo de experiência, ou ainda no estímulo à imitação dos figurinos e movimentos dos bailarinos, à repetição dos conteúdos destas letras? Pensamos sobre isto ou apenas "deixamos passar", pois concordando com um dos sujeitos da pesquisa, também nos sentimos tão impotentes a ponto de afirmar que "Eu não preciso entender, só preciso copiar e pronto"(Aluno 8, Transcrição mp3)?

Para Horkheimer \& Adorno (1985), a Indústria Cultural absolutiza a imitação já que na base do divertimento, planta-se a impotência. Esta relação entre o estético e o social é o cerne do pensamento de Adorno, juntamente com as ressalvas à razão tecnológica e instrumental, que nos desumaniza. Segundo o autor, esse tipo de "fazer artístico" forjado e exigido pela Indústria Cultural leva ao declínio da arte.

Apostando no universo onírico, as estratégias de marketing veem na infância um segmento promissor, pois os adultos, tentando compensar os espaços de sua ausência, confundem presente com presença, e muitas vezes cedem ao que é pedido- em alguns casos exigido - pelos filhos. Torna-se impossível, nesta perspectiva, endossar a ideia de infância como um período de limbo, com a atribuição de uma ideia de inocência que seja sinônimo de alheamento. A infância é também um produto da História, o que põe em crise o mito da "infância feliz". A esperança de uma infância que faça frente à corrupção adulta é absurda, pois esta mesma infância se insere num mundo de valores que nós mesmos temos criado, assumido ou reproduzido. Assim como nós, os pequenos interagem com estes constructos, pois são atores sociais.

Retomando as figuras apresentadas anteriormente, como representação das categorias teóricas e daquelas emergentes do trabalho de campo, nossa análise considerou a existência de intersecções entre elas, que nos levam a outras discussões:

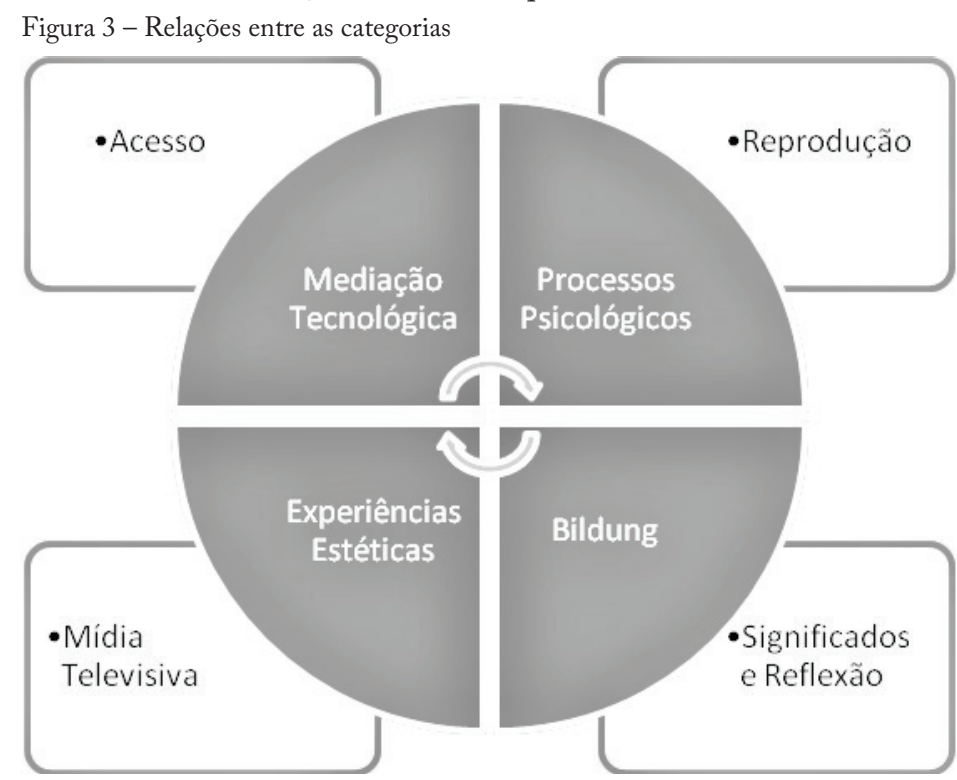


Do quadro acima, a partir das categorias denominadas Mediação Tecnológica e Acesso, podemos destacar a crescente facilitação para a comunicação de quaisquer tipos de informação, tanto as que podem ser formativas quanto as que carregam estereotipias e trazem prejuízos para a vida social, como por exemplo a erotização precoce. $\mathrm{O}$ excesso de informação, consequência da interseção entre estas duas categorias de nosso estudo, é algo com o qual ainda temos dificuldade para lidar, pois a velocidade com que os dados circulam exige certa habilidade para selecioná-los, organizá-los e, principalmente, dar-lhes significação. A superficialidade se torna evidente: não há tempo para se deter em nada, o amanhã sempre virá. Disto advém o fenômeno da descartabilidade nas sociedades capitalistas ocidentais e as montanhas de lixo virtual que preenchem, sobretudo, as nossas mentes.

Passando ao segundo ponto de intersecção do quadro de categorias, é interessante observar que o fenômeno de reprodução de comportamentos ${ }^{7}$ liga-se a processos psicológicos que são constitutivos da personalidade dos indivíduos em diferentes fases da vida. Em primeira instância, os processos imitativos na infância compõem as formas iniciais de aprendizado e também os laços afetivos primários. Posteriormente, na medida em que passa a conviver em outros ambientes, a criança atribui à figura do professor e/ou outros adultos significativos o papel de modelo, algo que na adolescência será transferido aos pares. Se o modelo próximo não é suficientemente saudável para o desenvolvimento psíquico, é bastante grande a possibilidade de que haja problemas no processo de individuação, essencial para o desenvolvimento de um Ego adequado à realidade.

Nas sociedades contemporâneas, a Indústria Cultural se encarrega de decidir o que é melhor para seus consumidores, adequando-os ao que se julga ser seu "modelo" mais favorável. E nós, no processo de construção da identidade social, pouco refletimos sobre aquilo que "compramos" e reproduzimos, perpetuando um ciclo a ponto de não sabermos mais onde seria seu início e seu fim, algo como a pergunta: escuto muito por que gosto ou gosto por que escuto muito?

Seguindo adiante nas análises da pesquisa, salientamos o terceiro ponto de intersecção entre as categorias, que diz respeito à ligação entre a Mídia Televisivia e as Experiências Estéticas. A presença da televisão nos lares mudou não apenas a maneira como se desfruta do tempo livre. Não é só do lazer que a televisão se ocupa. Em alguns contextos, a televisão exerce uma influência tão grande que o modelo de aprendizado não é mais o dos adultos próximos, como há pouco foi dito, mas o dos personagens criados e veiculados por este tipo de mídia. Tal situação conduz a uma espécie de padronização das experiências estéticas, pois se a audiência está ligada à vendabilidade, é preciso que estereótipos sejam reforçados insistentemente, para que sejam considerados necessários. Neste contexto - e somado ao fato de que as crianças têm passado muito tempo aos cuidados da televisão -, é de se compreender que os modelos de comportamento sejam em grande parte aprendidos deste veículo, algo que se agrava pelo fato de que pouco se encontra nas relações não-virtuais como contraponto da experiência televisiva. 
A padronização das experiências estéticas é uma das consequências de pensar as sociedades humanas como massas. A massa "precisa" de uma diversão condizente com a sua condição de dominada, caso contrário poderia organizar-se em seu tempo livre para transformar suas condições de existência, muitas vezes desfavoráveis.

Finalmente, ao aproximarmos o conceito de Bildung da categoria que nomeamos por Significados e Reflexão, temos a questão da atribuição de sentidos, algo intimamente relacionado com o processo de formação cultural e seu oposto: a semiformação. Adorno salienta o fato de que "[...] por inúmeros canais se fornecem às massas bens de formação cultural. Neutralizados e petrificados, no entanto, ajudam a manter no devido lugar aqueles para os quais nada existe de muito elevado ou caro" (2005, p. $6)^{8}$. O pouco exercício das capacidades interpretativas culmina numa espécie de nivelamento das consciências, algo extremamente danoso à vida pública (política).

É preciso ter claro que se a vida redunda em padronizações, perdemos a possibilidade de transcendência. A fragmentação da consciência nos processos alienatórios é um fato que confirma os danos de uma formação incompleta: a redução da vida em torno de poucos interesses. O poder que a realidade extrapedagógica exerce sobre a formação é uma constante nas conversas dos especialistas em educação e se constitui num desafio para todos nós, educadores profissionais ou não.

Gur- Ze'ev" destaca que a Bildung tem como meta "realizar o pleno desenvolvimento de cada ser humano" (2006, p. 2). Este deveria ser o propósito de qualquer tipo de formação, seja ela profissional, religiosa, técnica ou cultural: desenvolver ao máximo as potencialidades humanas a fim de que tenhamos uma sociedade mais justa. Afinal, a grande pergunta que deve pautar os processos educativos e a própria vida é uma reedição de uma questão filosófica básica: o que vamos fazer da humanidade do Homem?

\section{Referências}

ADORNO, T. Indústria cultural e sociedade. São Paulo: Paz e Terra, 2002.

. O fetichismo na música e a regressão da audição. In: Os Pensadores - Adorno, Textos Escolhidos. São Paulo: Editora Nova Cultural, 2000.

BENJAMIN, W. A Obra de Arte na época de suas técnicas de reprodução. In: Os pensadores - Benjamin, Adorno, Horkheimer e Habermas - Textos Escolhidos. São Paulo: Abril Cultural, 1980.

COSTA, B. C. Indústria Cultural: análise crítica e suas possibilidades de revelar ou ocultar a realidade. In: PUCCI, B. (Org). Teoria Crítica e Educação: a questão da formação cultural na Escola de Frankfurt. São Paulo: EDUFSCAR, 2007.

DUARTE, R. Teoria Crítica da Indústria Cultural. Belo Horizonte: Editora UFMG, 2003.

FABIANO, L. H. Bufonices culturais e degradação ética: Adorno na contramão da alegria In: RAMOS-DE-OLIVEIRA, N; ZUIN, A. A.; PUCCI, B. Teoria Crítica, Estética e Educação. Campinas: Autores Associados; Piracicaba: Editora UNIMEP, 2001.

HORKHEIMER, M.; ADORNO, T. Dialética do Esclarecimento: Fragmentos Filosóficos. Rio de Janeiro: Jorge Zahar, 1985. 
MARCUSE, H. A ideologia da Sociedade Industrial: O homem Unidimensional. Rio de Janeiro: Zahar Editores, 1982.

MERQUIOR, J. G. Arte e Sociedade em Marcuse, Adorno e Benjamin - ensaio crítico sobre a Escola Neohegeliana de Frankfurt. Rio de Janeiro: Edições Tempo Brasileiro, 1969.

PUCCI, B.; RAMOS-DE-OLIVEIRA, N.; ZUIN, A. Á. Adorno: o poder educativo do pensamento crítico. Petrópolis: Vozes, 2008.

PUCCI, B. Teoria Crítica e Educação. In: PUCCI, B. (Org). Teoria Crítica e Educação: a questão da formação cultural na Escola de Frankfurt. São Paulo: EDUFSCAR, 2007.

TAVARES, M. T. G. Uma escola: texto e contexto. In: GARCIA, R. L. (Org). Método: pesquisa com o cotidiano. Rio de Janeiro: DP\&A Editora, 2003.

TIBURI, M. Crítica da razão e mímesis no pensamento de theodor adorno. Porto Alegre: EdiPUCRS, 1995.

\section{Notas}

${ }^{1}$ Ao colocarmos como questão de pesquisa a fetichização do objeto artístico 'Música' postulamos como objetivos para o estudo o que segue: (a) problematizar a formação cultural na sociedade de consumo; (b) investigar, junto a uma classe de alfabetização, aspectos da cultura musical que se manifestam no cotidiano e são revelados na escola; (c) identificar que meios de persuasão utilizados pela Indústria Cultural estão implicados na construção do gosto musical do grupo estudado.

${ }^{2}$ Cabe salientar que houve uma convivência de quatro horas diárias (cinco vezes por semana) com o grupo em questão

${ }^{3}$ Em artigo intitulado Música, Indústria Cultural e Limitação da Consciência. In: Revista Mal-Estar e Subjetividade. Vol. VIII; No 4; p. 1143-1176. Fortaleza: dez/2008. Disponível em: <http://www.unifor.br/ joomla/joomla/images/pdfs/pdfs_notitia/2989.pdf>. Acesso em: ago. 2014.

${ }^{4}$ Idem referência anterior

${ }^{5}$ Conceito de ascese na música encontrado em ADORNO, 2000, p. 71.Horkheimer e Adorno (1985) apontam como instrumentos de dominação "a linguagem, as armas e por fim as máquinas” (p. 48) num contexto em que "a cultura deixou de ser uma decorrência espontânea da condição humana (...) para se tornar mais um campo de exploração econômica” (DUARTE, 2003, p. 9).

${ }^{6}$ Horkheimer e Adorno (1985) apontam como instrumentos de dominação "a linguagem, as armas e por fim as máquinas" (p. 48) num contexto em que "a cultura deixou de ser uma decorrência espontânea da condição humana (...) para se tornar mais um campo de exploração econômica” (DUARTE, 2003, p. 9).

${ }^{7}$ Acrescentamos aqui imagens, movimentos corporais, canções, modos de vestir, etc.

${ }^{8}$ ADORNO, Theodor. Teoria da Semicultura. In: Primeira Versão. Porto Velho, ano IV, No191, Volume XIII Maio/Agosto 2005 Disponível em: <http://www.primeiraversao.unir.br/atigos_pdf/191_.pdf >.Acesso em: ago. 2014.

${ }^{9}$ GUR-ZE’EV, Ilan. A Bildung e a Teoria Crítica na Era da Educação Pós-Moderna. In: Linhas Críticas, Brasília, v. 12, n. 22, p. 5-22, jan./jun. 2006. Disponível em: <http://periodicos.unb.br/index.php/linhascriticas/article/view/1673/1296>. Acesso em: ago. 2014. 
*Técnica em Assuntos Educacionais no Instituto Federal de Educação, Ciência e Tecnologia do Rio Grande, Rio Grande, Rio Grande do Sul, Brasil.

\section{Correspondência}

Thais de Oliveira Nabaes - Instituto Federal de Educação, Ciência e Tecnologia do Rio Grande do Sul, IFRS - Campus Rio Grande. Rua Engenheiro Alfredo Huch, Vila Santa Tereza, CEP: 96201460, Rio Grande, Rio Grande do Sul - Brasil.

E-mail: nabaes.prof@ibest.com.br

Recebido em 10 de setembro de 2015

Aprovado em 22 de março de 2016 